\title{
Impact factor, Associate Editors, acknowledgements and new editorial rules
}

We were extremely pleased with the new impact factor of 0.966 of the Journal of Applied Oral Science (JAOS) in the Dentistry, Oral Surgery \& Medicine category of the 2010 Journal Citation Reports (JCR) Science Edition, which represented a 2.5 -fold increase as compared with the 0.384 in the previous year. This achievement was an important indicator of the improvement in the international visibility of the JAOS. Our expectation is the impact factor and respect to the JAOS will continue to grow among the members of the scientific community.

In 2012 the JAOS will have the precious help of Associate Editors who were appointed by Dr. José Carlos Pereira, the current Dean of the Bauru School of Dentistry, University of São Paulo. The participation of the Associate Editors will certainly decrease the amount of time in the reviewing process, one of the main goals of all scientific journals.

It is a good time to thank all reviewers and authors. We also have to thank the National Council for Scientific and Technological Development (CNPq), the Foundation for the Coordination of Higher Education and Graduate Training (CAPES) and the University of São Paulo for the financial support. We always emphasize the JAOS is published by our dental school, a non-profit making institution, so that the support from the federal and state governments is the only financial source to our journal.

New editorial rules will soon be announced. The main change in the submission process will be related to the cost of the editing of manuscripts, which will now be under the authors' responsibility. Due to budget restrictions, unfortunately the JAOS will no longer be able to finance this important part of the publication process. We count on everyone's comprehension.

Please feel free to contact us through our e-mail address: jaos@usp.br. We also invite all readers, contributors and reviewers to visit our free complete online collection at http://www.scielo.br/jaos.

Finally, we take advantage of this editorial to wish all of Happy Holidays! With our best regards,

\author{
Carlos F. Santos \\ DDS, MSc, PhD, Professor \\ Editor-in-Chief \\ Journal of Applied Oral Science
}

